\title{
High-flux/high-temperature solar thermal conversion: technology development and advanced applications
}

\author{
Manuel Romero* and José González-Aguilar \\ IMDEA Energy Institute, Ramón de la Sagra 3, 28935 Móstoles, Spain
}

\begin{abstract}
Solar Thermal Power Plants have generated in the last 10 years a dynamic market for renewable energy industry and a pro-active networking within R\&D community worldwide. By end 2015, there are about $5 \mathrm{GW}$ installed in the world, most of them still concentrated in only two countries, Spain and the US, though a rapid process of globalization is taking place in the last few years and now ambitious market deployment is starting in countries like South Africa, Chile, Saudi Arabia, India, United Arab Emirates or Morocco. Prices for electricity produced by today's plants fill the range from 12 to $16 \mathrm{c} € / \mathrm{kWh}$ and they are capital intensive with investments above $4000 € / \mathrm{kW}$, depending on the number of hours of thermal storage. The urgent need to speed up the learning curve, by moving forward to LCOE below $10 \mathrm{c} € / \mathrm{kWh}$ and the promotion of sun-to-fuel applications, is driving the $\mathrm{R} \& \mathrm{D}$ programmes. Both, industry and $\mathrm{R} \& \mathrm{D}$ community are accelerating the transformation by approaching high-flux/high-temperature technologies and promoting the integration with high-efficiency conversion systems.
\end{abstract}

\section{Introduction}

Solar Thermal Power Plants (STPP) have generated, in the last 10 years, a dynamic market for renewable energy industry and a pro-active networking within R\&D community worldwide. By end 2015, there are about 5 GW of STPP installed in the world, most of them still concentrated in only two countries, Spain and the US, though a rapid process of globalization is taking place in the last few years and now ambitious deployments are starting in countries like South Africa, Chile, Saudi Arabia, India, United Arab Emirates or Morocco [1]. However, Concentrating Solar Power (CSP) technologies are extremely urged to speed up their learning curves because of the high competition and drastic reduction of costs of other renewable energy technologies and the need of optimizing dispatch and grid integration for markets with high penetration of solar and wind.

Prices for electricity produced by today's STTP fill the range from 12 to $16 \mathrm{c} € / \mathrm{kWh}$ depending on the irradiation level and most importantly on the financing conditions and they are capital intensive with investments above $4000 €$ / $\mathrm{kW}$, depending on the number of hours thermal storage [2]. However, most commercial initiatives are still scaled-up projects based upon technological developments and concepts that matured in the 1980 s and 1990s. They are projects still based on conservative schemes and technologies, which do not exploit the enormous potential of concentrated solar energy. Commercial projects use technologies of parabolic

\footnotetext{
* e-mail: manuel.romero@imdea.org
}

troughs with low concentration in two dimensions and linear focus, or systems of central tower and heliostat fields, operating with thermal fluids at relatively modest temperatures [3]. The most immediate consequence of these conservative designs is the use of systems with efficiencies about $20 \%$ nominal in the conversion of direct solar radiation to electricity; the tight limitation in the use of efficient energy storage systems; the high water consumption and land extension due to the inefficiency of the integration with the power block; the lack of rational schemes for their integration in distributed generation architectures and the limitation to reach the temperatures needed for the thermochemical routes used to produce solar fuels like hydrogen [4].

The urgent need to speed up the learning curve, by moving forward to LCOE below $10 \mathrm{c} € / \mathrm{kWh}$ and the promotion of sun-to-fuel applications, is driving the $R \& D$ programmes. Both, industry and R\&D community are accelerating the transformation by approaching high-flux/ high-temperature technologies and promoting the integration with high-efficiency conversion systems.

\section{Current status of Concentrating Solar Power}

From the 1970s to the 1990s, the development of solar thermal electricity (STE) technologies remained restricted to few countries and only few, though important, research institutions and industries were involved. The situation dramatically changed in 2007 with the approval of specific feed-in-tariffs (FIT) or power purchase agreements (PPA) in Spain and the US. Both countries with more than $4 \mathrm{GW}$ of projects already in operation at the end of 2014 have been 


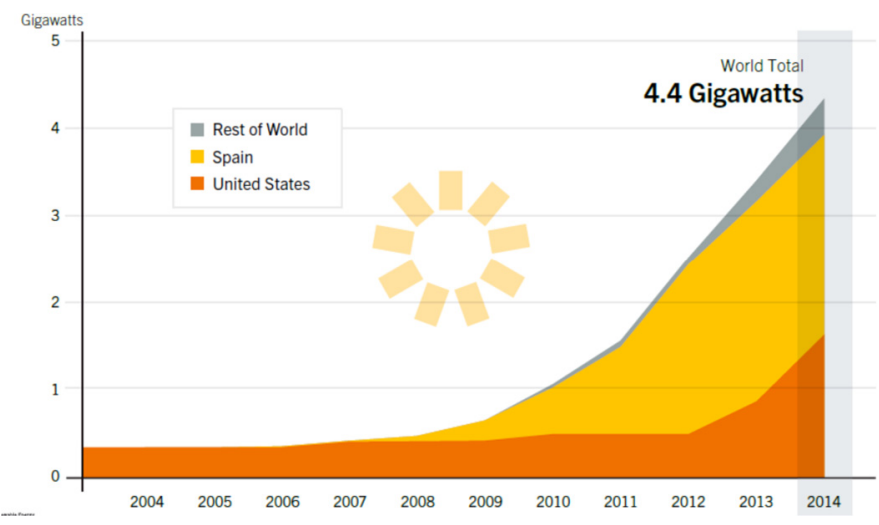

Fig. 1. Accumulated capacity installed [1].

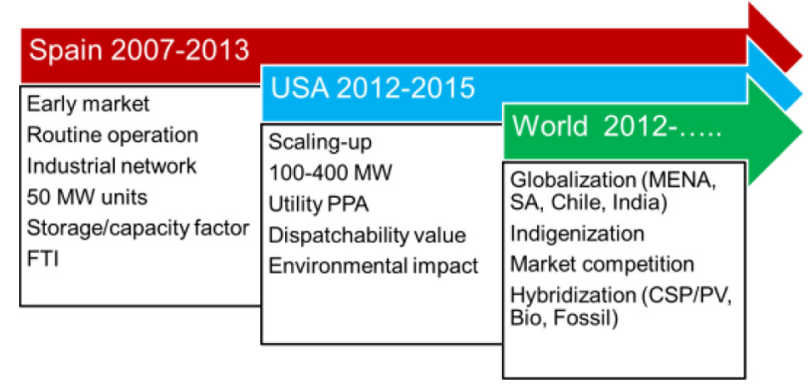

Fig. 2. Concentrating Solar Power (CSP) market development waves since 2007 .

the key drivers for market implementation (Fig. 1). Other countries have recently started specific policies to support CSP favouring the globalization of the technology. Subsequently a number and variety of engineering and construction companies, consultants, technologists and developers committed to STE were rapidly growing in the period 2008-2014.

As depicted in Figure 2, the market development process has three clear periods. First period between 2007-2013 has been totally led by Spain because of the adequate FIT policy leading to the construction of 50 STTP with total power of $2.3 \mathrm{GW}$. Typical unitary sizes of projects were $50 \mathrm{MWe}$ with parabolic trough being the technical solutions for most of them. This early market period served to demonstrate routine operation by choosing conservative designs and the validation of first commercial projects implementing molten salt thermal storage of about seven hours.

The second period led by the US has the peak between 2012 and 2015 and its distinct feature is the significant scaling up of the systems beyond 100 MWe (Ivanpah, Solana, Crescent Dunes, Mojave or Genesis) and the strong need of optimizing dispatchability value because of the highly demanding PPA by the utilities. Typical PPA with utilities (time of delivery value) is imposing a selling price $\$ 0.14 / \mathrm{kWh}$. Commissioning and routine operation become more complex (3-4 years from groundbreaking to commissioning). Environmental impact becomes essential in the design of the projects: visual impact, glint and glare, birds, water.
The third market wave represents globalization of the technology, being additional challenges the indigenisation of components, the competitive bidding and the hybridization with other energy sources. Main countries leading the projects nowadays are Morocco and MENA, Chile, China, South Africa and India. Figure 3 illustrates current CSP projects around the world according to Solar Power And Chemical Energy Systems (SolarPACES), an implementing agreement of the International Energy Agency (IEA) [5]. SolarPACES estimates that worldwide overall capacity of CSP is $10.1 \mathrm{GW}$, including operational plants as well as plants under construction and in development stages.

\section{Cost reduction}

In 2010, the IEA elaborated a first report including the globalization of STE commercial deployment for the future energy scenario. At that time, IEA started to consider that STE would play a significant role among the necessary mix of energy technologies for halving global energy-related $\mathrm{CO}_{2}$ emissions by 2050 [6]. This 2010 scenario would require capacity addition of about $14 \mathrm{GW} /$ year (55 new STPP of $250 \mathrm{MW}$ each). In 2014, the IEA presented an updated technology roadmap on STE [7]. Although it confirms that STE has grown less than expected in the first IEA CSP roadmap, STE roadmap maintained a STE's share of global electricity of $11 \%$ in 2050 , which means 1 TW of installed CSP capacity by 2050.

However, the competition with photovoltaics, which has become cost competitive with fossil fuels without subsidies in an increasing number of countries, has introduced an important stress to the developers of STE. They have been forced to move from strategies oriented to early commercialization markets based upon special tariffs, to strategies oriented to a massive production of components and the development of large amounts of projects with less profitable tariffs. This situation has been speeding up the implementation of larger capacity STE plants and/ or second-generation technologies, even though in some cases still some innovations are under assessment in early commercialization plants or demonstration projects.

LCOE value may be reduced up to an additional $30 \%$ when moving to future sites with very high direct normal irradiance. Figure 4 shows the normalized analysis carried out by the European Industry Association of Solar Thermal Electricity (ESTELA). The analysis reveals the impact on cost reduction after the implementation of $30 \mathrm{GW}$ where it is predicted 25-year PPA prices of $10 \mathrm{c} € / \mathrm{kWh}$ by 2020 for a $150 \mathrm{MW}$ reference plant with four-hour thermal storage [8]. The projected evolution of levelized electricity costs of different STE technologies is illustrated in Figure 5. The reduction in electricity production costs should be a consequence, not only of mass production but also of scaling-up and R\&D. The technology roadmap promoted by the European Industry Association in 2010 states that when most of the improvements currently under development are expected to be implemented in new plants, energy production boosts greater than $10 \%$ and cost decreases up to $20 \%$ are expected to be achieved. Furthermore, economies of scale resulting from plant size increase will 


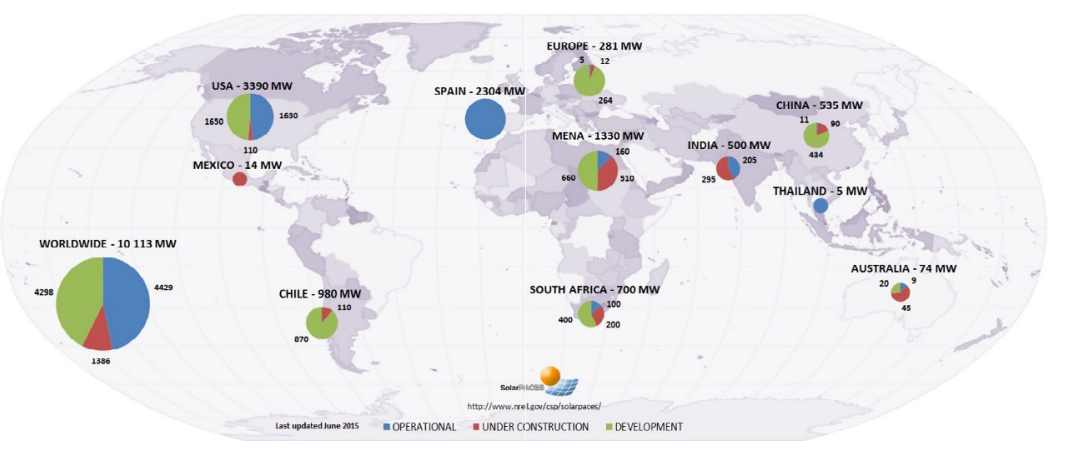

Fig. 3. Accumulated capacity of Concentrating Solar Power (CSP) worldwide.

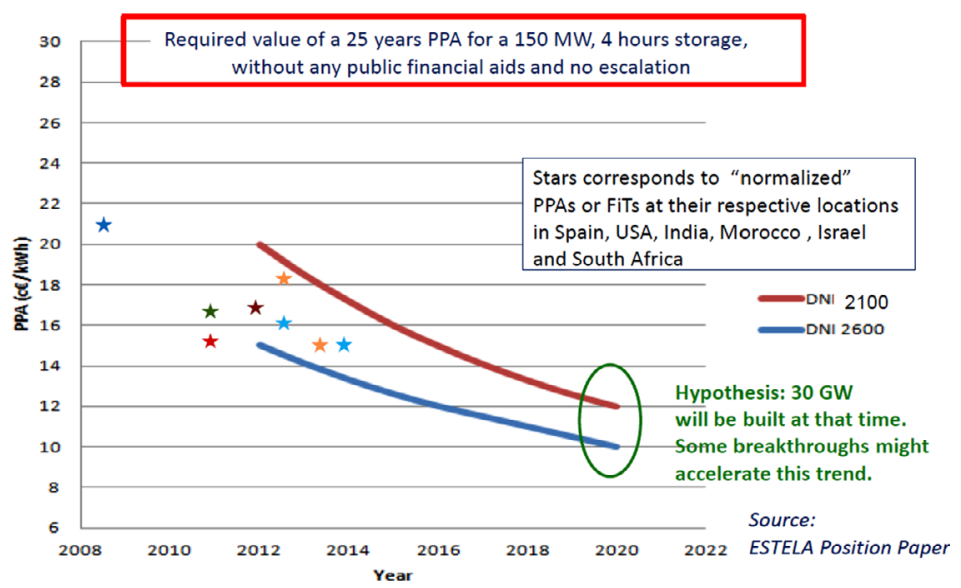

Fig. 4. Cost reduction: the view from the European Industry (source: ESTELA).

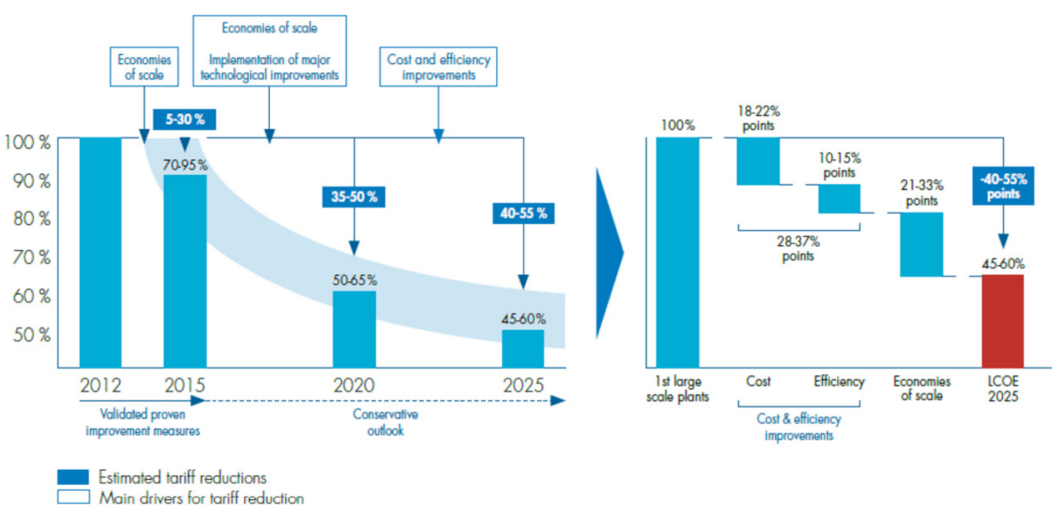

Fig. 5. Expected LCOE reduction from 2012 to 2025 [8,9].

also contribute to reduce plants' CAPEX per MW installed up to $30 \%$. STE deployment in locations with very high solar radiation further contributes to the achievement of cost competitiveness of this technology by reducing costs of electricity up to $25 \%$.

All these factors can lead to electricity generation cost savings up to $50 \%$ by 2025 , reaching competitive levels with conventional sources (e.g. coal/gas with stabilized electricity costs $<10 \mathrm{c} € / \mathrm{kWh})$. This objective is nowadays promoted by the European Commission in Horizon2020 for the year 2020 in consultation with industry sector and R\&D centers for the revision of the SET-Plan.

\section{R\&D challenges in Concentrating Solar Power}

Some reports have recently been published addressing the R\&D challenges in CSP. The ESTELA report on STE: strategic research agenda $2020-2025$ is probably the most relevant indicating guidelines in order to reduce STE costs. R\&D topics are oriented towards three main objectives: increase efficiency and reduce generation, operation and maintenance costs; improve dispatchability and improve environmental profile [8]. IEA have also provided some hints in its technology roadmap on STE [7]. 


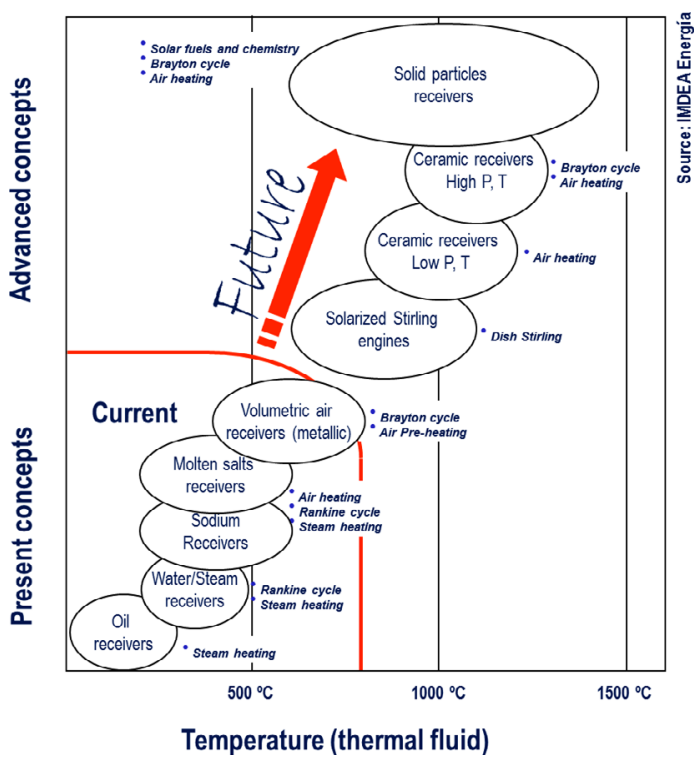

Fig. 6. Concentrating Solar Power (CSP) towards high-flux/ high-temperature technologies with efficient conversion.

There is a consensus among stakeholders that next generation technologies should be based upon the use of higher flux and temperature to increment the thermal efficiency conversion (Fig. 6), this implies the use of ceramic materials and the development of solar volumetric receivers, particle receivers and reactors, as well as the use of supercritical fluids [10].

In optical engineering, the technology evolution is heading to ultra-modular concentrators of plug-and-play type with high degree of automatism, reliability and flexible unmanned operation that might be subject to integration in different environments, including semi-urban. At component level, new mirrors will require $R \& D$ activities on light reflective surfaces, antisoiling coatings and high reflective.

In heat transfer, the R\&D is accelerating the development of new thermal fluids for operation at higher temperatures; new thermal (sensible heat and phase change) and thermochemical energy storage systems; solar receivers with advanced volumetric absorbers or clouds of particles for higher apparent absorptivity and development of drycooling at power block for avoiding water consumption.

Energy conversion is looking for the use of new turbomachinery and cycles making use of supercritical fluids as well as the integration of direct conversion systems like TPV (thermal PV), high-temperature thermoelectric converters or thermionic energy conversion.

In particular, STE based on central receiver technologies will need improvements in the heliostat field as a result of better optical properties, lower cost structures, and better control. In general terms, optical performance and durability of existing heliostats is acceptable (95\% availability and beam quality below $2.5 \mathrm{mrad}$ ), therefore $\mathrm{R} \& \mathrm{D}$ resources should focus basically on cost reduction.

Development of water/superheated steam and advanced air-cooled volumetric receivers using both wiremesh absorbers and ceramic monoliths is the subject of various projects. Dual-aperture receivers for water/ steam and volumetric receivers for air need further development for scale-up, materials durability and thermal efficiency.

Heat storage is another key issue for CRS development. The new developments in air-cooled receivers have led to the development of advanced thermocline storage systems making use of packed-bed ceramic materials. This system has shown excellent performance for small units of a few MWh but pressure losses and design restrictions appear when size is increased.

Finally, more distributed control architectures, system integration and hybridization in high-efficiency electricity production schemes should be developed as already mentioned for trough systems.

\section{R\&D programs}

\subsection{Europe - EERA - Integrated Research Program STAGE-STE}

The Strategic Energy Technology Plan (SET-Plan) establishes the policy at European level in order to accelerate the development and deployment of cost-effective low carbon technologies for the achievement of Europe's 2020 targets and vision on greenhouse gas emissions, renewable energy and energy efficiency. The European Energy Research Alliance (EERA), which was launched in 2008, is one of the initiatives of the SET-Plan. Within EERA, the Joint Programme on Concentrated Solar Power (EERA JPCSP), which is currently coordinated by CIEMAT, was formally approved in April 2011. From February 2012, the Integrated Research Program STAGE-STE (Scientific and Technological Alliance for Guaranteeing the European Excellence in Concentrating Solar Thermal Energy) supports the EERA JP-CSP. STAGE-STE gathers 42 members, all EU research institutions partners of EERA JP-CSP plus a significant number of additional organizations, including those from non-EU countries. The overall project budget is 21.198.352 $€$, where the European Commission Contribution is 9.997.207 $€$.

Other European actions exist through the EU Framework Programme for Research and Innovation: the panEuropean STE research infrastructure "EU-Solaris" within the European Strategy Forum on Research Infrastructure (ESFRI) launched in April 2002 on new research infrastructure includes; 'Solar ERANET' within the European Research Area Net (ERANET) that focuses on establishing joint actions in the form of public-private partnerships; or the 'Solar Facilities for the European Research Area' (SFERA).

\subsection{Sunshot - USA}

The SunShot Imitative was launched in 2011 and supervised by the US Department of Energy (DOE). Its goal is to reduce the price of solar energy systems by about $75 \%$ between 2010 and 2020 and then to make solar energy cost competitive with other forms of energy, without subsidies, by the end of the decade. Figure 7 illustrates the strategy of cost reduction through technical improve- 


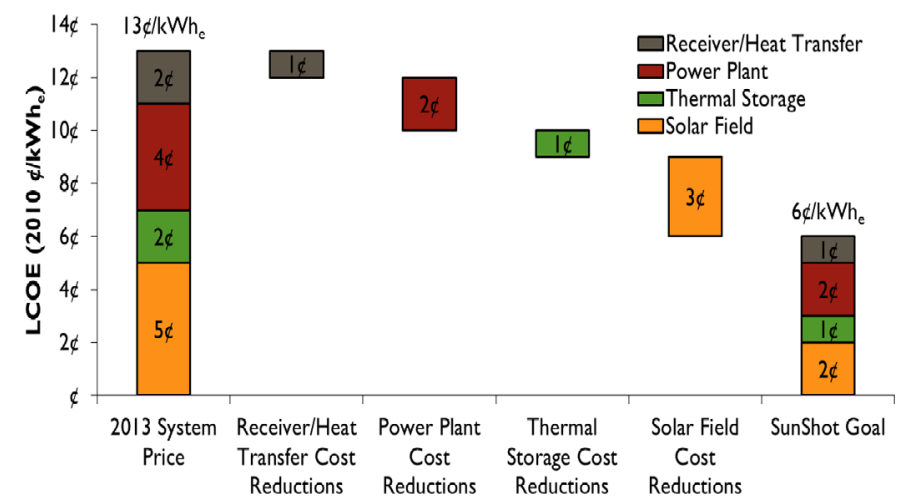

Fig. 7. Expected LCOE reduction in SunShot Concentrating Solar Power (CSP) program.

ments due to $\mathrm{R} \& \mathrm{D}$ programs. It is particular relevant the targets defined by DOE on CSP and that establish the R\&D calls.

Any development on solar fields searches dramatically reducing the cost of the collector field $\left(<\$ 75 / \mathrm{m}^{2}\right.$, compare to $\left.2010 \sim \$ 250-\$ 300 / \mathrm{m}^{2}\right)$ while improving or maintaining optical efficiency (optical error $<3 \mathrm{mrad}$, sustain wind speed $>85 \mathrm{mph}$, and lifetime $>30$ years). Thus main research topics in this area concern the development of high optical accuracy reflectors, the reduction of collector structure weight and material, the development of clean and rapid manufacture, assembly and installation methods and highly efficient tracking and control and accurate metrology tools and strategies to reduce operations and maintenance (O\&M) costs.

A second requirement concerns solar receivers that must significantly increase operating temperatures $\left(>720^{\circ} \mathrm{C}\right)$, efficiency $(>90 \%)$ and lifetime $(>10,000$ cycles $)$ at costs smaller than $\$ 150 / \mathrm{kW}$ th. Therefore, R\&D activities focus on the development of novel solar selective coatings and new receiver designs.

Electricity generation through high-temperature power cycles requires a net cycle efficiency higher than 50\%, they should involve dry cooling and investment cost lower than $\$ 900 / \mathrm{kWe}$. Then R\&D is oriented to develop hightemperature power cycles, solid-state power conversion techniques and hybrid cycles.

\subsection{Asia - Solar Mission (India), Australia}

In India, the Jawaharlal Nehru National Solar Mission was launched on the 11th January, 2010 with the ambitious target of deploying 20,000 MW of grid connected solar power by 2022. In order to achieve this goal, the Solar Mission is supported by a R\&D program led to developed excellence R\&D centres on solar energy, pilot scale STE plants, amongst others.

China has a significant number of public centers like the Institute of Electrical Engineering of the Chinese Academy of Science and industry related with CSP like Himin Solar or Supcon. Recently, September 2015, the China National Energy Administration's (NEA) has published a notice on the organization of $1 \mathrm{GW}$ of CSP Demonstration Projects during 2016-2017.
Australian Solar Thermal Research Initiative (ASTRI) is a consortium composed by Australian research institutions collaborating to deliver cost reductions and dispatchability improvements. It is the tool funded by the Australian Renewable Energy Agency (ARENA, a commercially oriented agency, established on 1st July 2012 by ARENA Act 2011) to position Australia in concentrating solar thermal (CST) power. ASTRI target is to lower the cost of solar thermal power from 26.5 to 12 cents a kilowatthour by 2020 . The research program is established on four main objectives or nodes: reduce capital, increase capacity factor, improve efficiency, and add product value.

\subsection{Africa - MENA, South Africa}

In 2011, South Africa promulgated the Integrated Resource Plan (IRP) 2010-2030. The main objective was to add 56,500 MW of electricity by 2030, compared with current capacity of about 38,000 MW, mostly produced by Eskom (the national utility) coal-fueled power stations. From the new capacity, 21,534 MW (38\%) is allocated to renewable energy technologies, and 1200 MW (2.1\%) would assigned to CSP. The implementation of the IRP is mainly carried out by the Renewable Energy Independent Power Producers' Procurement Programme (REIPPPP). Here private developers are able to bid for allocations and the renewable electricity will be purchased by Eskom and supplied to the national grid. The program is driving $R \& D$ with relevant stakeholders like the University of Stellenbosch.

Moroccan Solar Plan (MSP) targets at least 2 GW of solar capacity by 2020 and a simultaneous development of a local solar industry. Morocco in setting up its own CSP R\&D centre, under the auspices of Masen, the Moroccan Agency for Solar Energy. MENA region is especially active in R\&D with the creation of relevant institutions like MASDAR in Abu Dhabi, QEERI in Qatar or KA CARE in Saudi Arabia.

\subsection{Latin America - Chile and Mexico}

Demonstration projects and associated R\&D are emerging in Mexico and Chile and mobilizing other countries like Brazil and Argentina. In Mexico, there is a strong R\&D 
community with special relevance of the Institute of Renewable Energy from UNAM in Cuernavaca and the Central Receiver Test Center in Sonora. According to the National Energy Strategy (ENE) 2013-2027 of the Mexico's Government, the country should diversify and optimize the electric generation park. Based on this, the ENE includes a goal to increase the participation of RE sources in electricity generation to $35 \%$. The policy in the country is advancing to promote CSP plants through liberalization of the market and $\mathrm{R} \& \mathrm{D}$ networking through several initiatives funded by CONACYT.

Chile has a National Energy Strategy 2012-2030 that establishes the targets in energy policy for the next decades. Among the objectives, it is relevant to mention up to 25 GW of renewable energy power by 2025 . Several projects accounting for about $1 \mathrm{GW}$ of STPP are already in construction in North Chile where very high solar irradiance is guaranteed. The public $\mathrm{R} \& \mathrm{D}$ is nucleated in the Solar Energy Research Center SERC Chile that integrates most of the universities and foundations related with solar energy research in the country. A specific facility promoted for CSP research is the Solar Platform of Atacama Desert in Antofagasta.

The authors gratefully acknowledge "Comunidad de Madrid" and "European Social Fund" for its financial support to the ALCCONES Project through the Programme of Activities between Research Groups (S2013/MAE-2985). Thanks are also due to the support of the European Union's Seventh Framework Research Programme STAGE-STE (Scientific and Technological Alliance for Guaranteeing the European Excellence in Concentrating Solar Thermal Electricity, ENERGY. 2013.10.1.10).

\section{References}

1. REN21, Renewables 2015 Global Status Report (REN21 Secretariat, Paris, 2015). ISBN: 978-3-9815934-6-4. http:// www.ren21.net

2. International Renewable Energy Agency (IRENA), Concentrating solar power, Renew. Energy Technol. Cost Anal. Ser. 1 (2012). http://www.irena.org/Publications

3. M. Romero, J. González-Aguilar, Solar thermal CSP technology, WIRE's Energy Environ. 3, 42 (2014)

4. M. Romero, A. Steinfeld, Concentrating solar thermal power and thermochemical fuels, Energy Environ. Sci. 5, 9234 (2012)

5. SolarPACES: http://www.solarpaces.org/csp-technology/ csp-projects-around-the-world (2015)

6. IEA, Energy technology perspectives 2010 - Scenarios and strategies to 2050 (IEA Publications, Paris, 2010). ISBN: 97892-64-08597-8

7. IEA, Technology roadmap: solar thermal electricity (IEA Publications, Paris, 2014). http://www.iea.org

8. European Solar Thermal Electricity Association (ESTELA), Concentrating solar power on the road to 2030, ESTELA a.s. b.l. report (2015). http://www.estelasolar.org/our-activities/ communication-and-media/publications/

9. A.T. Kearney, Inc., Solar thermal electricity 2025, Clean electricity on demand: attractive STE cost stabilize energy production (A.T. Kearney GmbH, Dusseldorf, Germany, 2010). http://www.estelasolar.org/our-activities/communi cation-and-media/publications /

10. M. Romero, J. Gonzalez-Aguilar, E. Zarza, Chapter 42: Concentrating Solar Power, Energy Efficiency and Renewable Energy Handbook, 2nd ed., edited by D.Y. Goswami and F. Kreith (CRC Press, Boca Raton, Florida, 2015), 1237-1346, Online ISBN: 978-1-4665-8509-6, Print ISBN: 978-1-4665-8508-9

Cite this article as: Manuel Romero, José González-Aguilar, High-flux/high-temperature solar thermal conversion: technology development and advanced applications, Renew. Energy Environ. Sustain. 1, 26 (2016) 